\title{
Amistades peligrosas: Osteomielitis crónica en una paciente diabética con úlcera neuropática
}

\author{
Wendi Moreno Rodríguez ${ }^{\mathrm{a}}$, Antonio Ruiz Serrano ${ }^{\mathrm{b}}$
}

\begin{abstract}
a Médico Residente de $4^{\circ}$ año de Medicina Familiar y Comunitaria.

${ }^{\mathrm{b}}$ Especialista en Medicina Familiar y Comunitaria. Tutor de Residentes.

Centro de Salud Ciudad Real III.

Correspondencia: Wendi Moreno Rodríguez. Avda. Tablas de Daimiel 1, $4^{\circ}$ A. 13004. Ciudad Real Correo electrónico: wendi_moreno6@hotmail.com

Caso clínico presentado en el XII Congreso de Atención Primaria de Castilla-La Mancha, en formato póster (Cuenca, 12-14 de mayo de 2011).
\end{abstract}

Recibido el 9 de diciembre de 2012.

Aceptado para su publicación el 17 de junio de 2013.

\begin{abstract}
RESUMEN
La osteomielitis es una infección frecuentemente asociada como causa de una evolución tórpida de úlceras neuropáticas en pacientes con Diabetes Mellitus. Este grupo de pacientes muestran una tendencia mayor a las infecciones de los tejidos blandos y los huesos, en comparación con los pacientes no diabéticos. Las úlceras infectadas incrementan significativamente el riesgo de amputación. Presentamos el caso de una paciente diabética tipo 2 de 25 años de evolución que presentaba una úlcera neuropática de evolución tórpida.
\end{abstract}

Palabras Clave. Diabetes Mellitus. Neuropatías Diabéticas. Osteomielitis. Pie diabético.

\section{ABSTRACT}

Dangerous Liaisons: Chronic osteomyelitis in a diabetic patient with neuropathic ulcer Osteomyelitis is a common infection associated as a cause of slowly evolving neuropathic ulcers in patients with diabetes mellitus. This group of patients shows a greater tendency towards soft tissue and bone infections in comparison with non-diabetic patients. Infected ulcers significantly increase risk of amputation. We report the case of a type 2 diabetic patient with 25 years' evolution who had a slowly evolving neuropathic ulcer.

Key words. Diabetes Mellitus. Diabetic neuropathies. Osteomyelitis. Diabetic foot.

\section{INTRODUCCIÓN}

Se denomina pie diabético al conjunto de complicaciones vasculares, neuropáticas e infecciosas que pueden padecer en sus pies los pacientes con diabetes mellitus. Es la causa más frecuente de amputación no traumática en la población, de hecho, entre uno y dos tercios de los amputados son diabéticos, presentando 20 veces más riesgo que los no diabéticos ${ }^{1}$.

Los factores locales que favorecen la ulceración son la ausencia de sensibilidad, la neuropatía autonómica, la aparición de lesiones locales (hiperqueratosis, fisuras, xerosis), las deformidades del pie, la vasculopatía, la movilidad articular limitada, la historia previa de úlcera y amputación, y el uso de calzado inadecuado. Asimismo, se consideran factores de riesgo de amputación el no haber recibido educación sanitaria para diabéticos, la presencia de isquemia y neuropatía, la disminución de la sensibilidad vibratoria o un índice tobillo/ brazo por debajo de $0,45^{1-3}$.

Según Martos Medina et al., el $70 \%$ de las úlceras en los pies diabéticos son de origen neuropático puro ${ }^{2}$, entre el $15-20 \%$ son isquémicas y el otro 10$15 \%$ son de etiología neuroisquémica, lo que nos hace ver que la mayoría de las ulceraciones a las que tendremos que hacer frente serán de origen neuropático.

Las infecciones son una de las complicaciones habituales del pie diabético, un factor de riesgo de amputación y la causa más frecuente de hospitalización de estos enfermos, con estancias prolongadas ${ }^{3,4}$. Las infecciones se localizan en la piel y los tejidos blandos, pero no es infrecuente que el hueso se vea afectado ${ }^{3}$.

Existen numerosas clasificaciones para las úlceras en el pie diabético, pero ninguna está aceptada universalmente. La clasificación de Wagner es quizás 
la más utilizada y clasifica la úlcera en 5 grados en función de la profundidad y el grado de gangrena, desde el pie de riesgo hasta la gangrena extensa ${ }^{2,5,6}$.

\section{OBSERVACIONES CLÍNICAS}

Presentamos el caso de una mujer de 57 años de edad, hipertensa, con DM tipo 2 mal controlada metabólicamente, retinopatía y neuropatía diabética. Padece una úlcera neuropática de dos años de evolución, con desbridamiento quirúrgico intermitente y antibioterapia según el resultado de los cultivos. No alergias conocidas.

La paciente consulta por dolor en talón izquierdo de 48 horas de evolución, impotencia funcional a la deambulación, fiebre de $38,5^{\circ} \mathrm{C}$ y alteración del estado general. A la exploración física llama la atención palidez cutáneo-mucosa. Se observa una gran úlcera en el talón izquierdo, con signos inflamatorios y abundante exudado purulento. Tras la limpieza de la zona afecta con suero fisiológico, se observa un área de consistencia pétrea en el fondo de la úlcera que impresiona de hueso expuesto (Fig. 1).

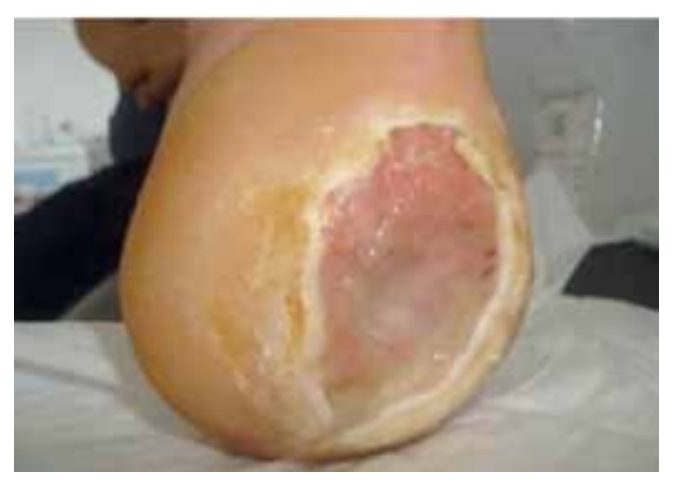

Figura 1. Extensa úlcera neuropática sobre un heloma (hiperqueratosis), con hueso expuesto.

Ante la alteración del estado general y el cuadro infeccioso, se decide la derivación al hospital de referencia para estudio radiológico y analítico.

En el servicio de urgencias la paciente se encuentra consciente y orientada, con palidez muco-cutánea y febril. En la exploración se aprecia movilidad normal de MMII, sin signos de TVP. Se palpan pulsos pedios bilaterales.

En la analítica realizada se aprecia aumento de reactantes de fase aguda (VSG, PCR, fibrinógeno), leucocitosis con desviación a la izquierda y anemia ferropénica en rango de transfusión ( $\mathrm{Hb}$ 7,2 $\mathrm{gr} / \mathrm{dl})$. En el cultivo de exudado se encuentran Pseudomona aeruginosa y Morgagnella morgagni.
La radiografía del pie muestra una imagen de pérdida importante de masa ósea de calcáneo con signos inflamatorios y abundante esclerosis, resorción cortical, formación de nidos óseos e importante reacción perióstica a dicho nivel, todo ello compatible con osteomielitis muy evolucionada (Fig. 2).

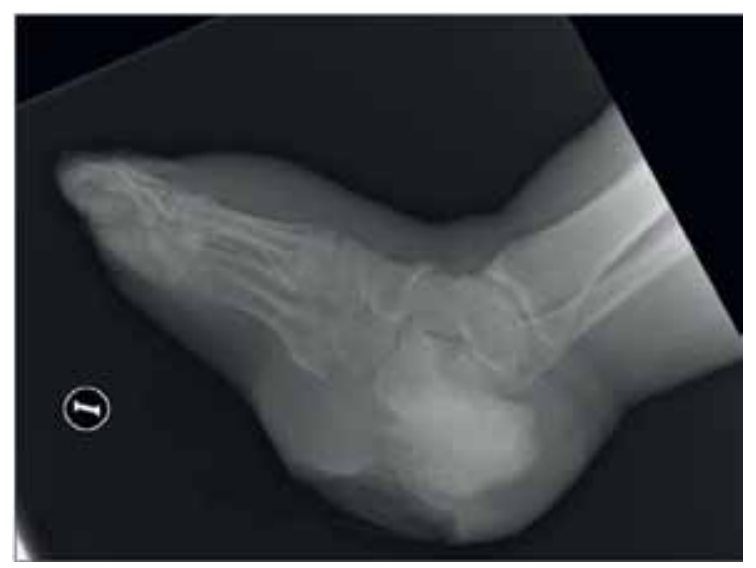

Figura 2. La radiografía muestra amplia destrucción del calcáneo y signos de osteomielitis.

Se pautó tratamiento antibiótico con clindamicina y levofloxacino oral según resultado de cultivo y antibiograma, despareciendo la fiebre y mejorando su estado general, así como el aspecto de la úlcera del talón (Fig. 3). Recibió el alta hospitalaria para seguimiento ambulatorio. Se le realizaron curas por el servicio de enfermería y quedó pendiente de valoración quirúrgica para una calcanectomia, al rechazar la paciente, por motivos personales, la amputación del pie.

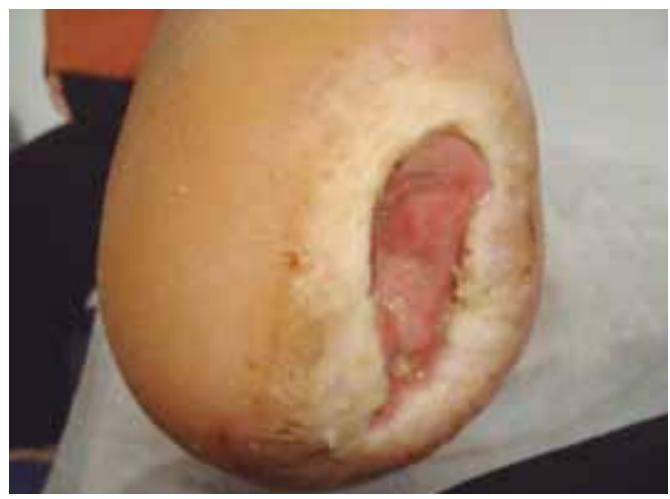

Figura 3. Mejoría de la úlcera tras el tratamiento antibiótico inicial.

La paciente, a los 20 días del alta hospitalaria, presentó un cuadro confusional agudo y proceso febril, por lo que precisó nuevamente ingreso hospitalario. Finalmente fallece con el diagnóstico de meningitis secundaria a sepsis por Pseudomonas. 


\section{COMENTARIOS}

Tal como comentamos, el pie diabético es la causa más frecuente de amputación no traumática en la población, con una incidencia de 6-8 amputaciones/1000 diabéticos al año $0^{7,8}$.

Las úlceras neuropáticas ocurren en las zonas de apoyo, favorecidas por la presión, la hipoestesia y los trastornos tróficos cutáneos debidos a la afectación del sistema nervioso autónomo². Si profundizan hasta el hueso se pueden complicar con una osteomielitis, como en el caso que describimos.

Aunque existen diferentes clasificaciones de úlceras neuropáticas, la más aceptada es la de Wagner. En nuestra paciente, según esta clasificación, la úlcera correspondería a un grado 3 (úlcera extensa y profunda, con celulitis, abscesos y osteomielitis). La radiografía simple debe ser el primer estudio en todo paciente con sospecha de osteomielitis, ya que nos puede dar el diagnóstico y descartar otros procesos ${ }^{7}$. Se requiere una pérdida de masa ósea entre el 30 y el $50 \%$ para que sea visible radiológicamente, lo que explica la demora de 10-21 días para que la lesión sea visible con esta técnica. Como indica en su genial artículo el profesor Boulton, la mejor forma de evitar amputaciones es "quitarles los zapatos y los calcetines al paciente y examinarle los pies" ${ }^{\text {. }}$.

El tratamiento de las úlceras neuropáticas incluye control metabólico, exploración vascular para descartar isquemia, valorar posible osteomielitis, desbridamiento, desinfección y descarga, así como antibioterapia según antibiograma ${ }^{8,10}$.

Es evidente que la evolución de la paciente no fue la esperada. Creemos que con la calcanectomía y casi seguro con la amputación, que no se realizó por respeto a la autonomía de la paciente, la sepsis se hubiera evitado y con ello la muerte de esta mujer joven. Desconocemos si se le explicó a la paciente el riesgo derivado de su rechazo a la intervención y si, de este modo, su decisión hubiese cambiado.

\section{BIBLIOGRAFÍA}

1. Gervilla Caño J, Soler González J. Ulcera en pie diabético. Formación Médica Continuada en Atención Primaria. 2010;17:143-4.

2. Martos Medina D, Morillas Suárez $C$, Torres Latorre MA. Tratamiento de úlceras neuropáticas grado $1 \mathrm{y}$ 2 de la escala de Wagner en pacientes diabéticos. Disponible en: http://www.ulceras.net/publicaciones/ ttoneuropaticasdionisiomartos.pdf. [consultado el 10/07/2013]

3. Real Collado JT, Valls M, Basanta Alario ML, Ampudia Blasco FJ, Ascaso Gimilio JF, Carmena Rodríguez R. Estudio de factores asociados con amputación, en pacientes diabéticos con ulceración del pie. Anales de Medicina Interna. 2001;18(2):59-62.

4. Barberán J. Infecciones en el pie diabético: importancia de las resistencias bacterianas. Enfermedades Infecciosas y Microbiología Clínica. 2009;27(6):315-6.

5. Gómez Hoyos E, Levy AE, Díaz Pérez JA, Cuesta Hernández M, Montáñez Zorrilla MC, Calle Pascual AL. Pie diabético. Seminarios de la Fundación Española de Reumatología. 2012;13(4):119-129.

6. Boada, A. Lesiones cutáneas en el pie diabético. Actas Dermo-Sifilográficas. 2012;103(5):348-356.

7. Gutiérrez Saborido D, Ruiz Blasco E, Carmona Espinazo F, García Olmedo O. Protocolo diagnóstico de la osteomielitis. Medicine. 2010;10(53):3591-3.

8. American Diabetes Association. Peripheral arterial disease in people with diabetes. Diabetes Care. 2003;26(12):333341.

9. Boulton AJ. The diabetic foot: from art to science. Diabetología. 2004;47(8):1343-53.

10. Blanes JI, Clará A, Lozano F, Alcalá D, Doiz E, Merino R. Documento de consenso sobre el tratamiento de las infecciones en el pie del diabético. Angiología. 2012;64(1):31-59. 